all the signs of vascular degeneration, including that of the capillaries and parenchyma, he is subject to vascular accident, especially if essential hypertension is added to and the kidney function is impaired. But both are starting from the same physiological angiospasm. This spasm is an important and early sign, worth watching and pointing the way to dangerous possibility years ahead, but it is only a part of the clinical picture and must be included in the whole.

As mentioned above, the symptom by itself is only the-first step of the accommodation of the body to new condition of vascular life. It is usually not accompanied by a local rise in blood pressure. But if, measured by Bailliart's method, the diastolic pressure will be raised as well, usually it comes much later, and it precedes for some time the ophthalmoscopic changes in the retinal vessels, and the prognosis becomes much more alarming. I will even ask the indulgence of the reader for a generalisation. One way of vascular degeneration, accompanied by normal or even moderately elevated blood pressure is not liable to local angiospasms, allows the reaching of the ripe age, is characterised chiefly by a. v. compression and may be tortuosity of the arteries. This is the picture of senile fundus. The other one, in similat conditions of the blood pressure or with a very elevated sphygmomanometric reading, is liable in addition to local angiospasm, involving a whole area of the vascular tree, leading to vascular accidents or even exitus laethalis; in fundi the predominant picture is the change of the arterial wall and volume, haemorrhages, retinomalacia, etc. The clue in the diagnosis would be the sphygmometric, dynamometric (for the retina) and oscillometric readings together with the general clinical picture.

\title{
BIBLIOGRAPHY
}

BAILLIART.-La circulation retinienne, 1923.

DUKE-ELDER. - Text-book of ophthalmology.

PACHON ET FABRE.-Clinical curves of the cardiac function.

\section{REPORT ON A CASE OF HYDROPHTHALMIA (BUPHTHALMOS)}

BY

\section{E. Epstein, Major, R.A.M.C.}

THE following case is thought worth recording, for whereas the diagnosis of megalocornea might presumably have been made previously, the recent development of acute glaucoma in the right

* Received for publication, September 7, 1945. 
eye suggests that the case is one of arrested hydrophthalmia that has "decompensated" to use an old cardiological term. It illustrates the difficulty of making a definite diagnosis of megalocornea in the absence of a clear familial history and indicates the need for caution in such cases.

Dvr. H., aged 24 years, was enlisted July, 1939, and categorised A1. He served with the B.E.F., M.E.F., C.M.F., and finally B.L.A. without ever complaining about his eyes until July-August, 1944, whilst in France, when he began to have a lot of headachesunusual for him. He thought that the great amount of night driving recently done had provoked them. On August 16, 1944, he was sent for ophthalmic examination on account of these headaches and was ordered the following glasses:-V.R. 6/60. - 5.00 D.Sph. $=6 / 36$. V.L. $6 / 18$. -0.50 D.Sph. $\overline{\mathrm{c}}-1.00$ D.C. ax. $180^{\circ}=6 / 9$ and recategorised $\mathrm{A} 3$ in keeping with the Army visual standard of 4 . The spectacles helped but he still had headaches at times. Towards the end of January, 1945, some dust blew into the left eye and on rubbing it he noticed that the right vision was extremely dim. He reported ill again and was examined at a hospital in Belgium where the diagnosis of acute glaucoma was made. When seen by me on March 17, 1945, the condition was as follows:-Right eye : absolute glaucoma, injected bulb, steamy cornea, semi-dilated and fixed pupil. Fundus seen with difficulty but deep glaucomatous cupping and many scattered round haemorrhages observed. Tension: R.=32, L. $=11 \mathrm{~mm} . / \mathrm{Hg}$ Schiötz. Both eyes have large corneae: R. horizontal diam. $14 \mathrm{~mm}$.; Vert. diam. $14 \mathrm{~mm}$., L. hor. diam. $13 \frac{1}{2}$ mm.; vert. diam. $13 \frac{1}{2} \mathrm{~mm}$. Arcus juvenilis lower quadrants $R$. and L. Wide limbus $R>L$. No corneal opacities except a very small "chalk" ring on right. Slit-lamp examination showed scattered numerous dots of pigment on and in endothelium with tendency to aggregate into a central column as Krukenberg spindles. No splits of Descemet's, right or left. Curvature of centre of both corneae more than usual, radius of $R .7 \cdot 5$, L. $7 \cdot 0 \mathrm{~mm}$. The sclera is thin R. $>\mathrm{L}$. Anterior chambers are deep, R. 6.5 -7 mm.; L. $6 \mathrm{~mm}$. Iris, R. and L., slightly atrophic having a frayed appearance. On transillumination the atrophy is seen to affect mainly the periphery and the pupil edge just within the sphincter. R. affected more than $L$. Lenses thicker than normal, sagittal diameter being $5 \mathrm{~mm}$. They are nontremulous. Fundi: R. as above, L. normal. L. field is normal, periphery and blind spot, using $1 / 330,1 / 1,000$ and $10 / 1,000$ white targets.

$$
\begin{array}{r}
\text { Refraction:- R. no P.L. }-3.0 \text { D.Sph. } \bar{c}-2.0 \text { D.C. ax. } 165^{\circ} \\
\text { L. } 6 / 12+-0.5 \text { D.Sph. } \bar{c}-2.0 \text { D.C. ax. } 5^{\circ}=66 \text {. }
\end{array}
$$

The right eye has the appearance of being larger than the left and the above refraction is in keeping with an axial enlargement although the relative retro-position of the lens in the right eye 
might possibly account for the refractive difference. A good photograph taken in 1940 shows the right eye then to be larger in appearance.

There has at various times been much controversy whether megalocornea is an entity or an arrested hydrophthalmia. The work of Kayser, Seefelder, Kestenbaum, Grönholm, Friede, quoted by Anderson ${ }^{1}$, indicates that megalocornea as a definite entity does exist and pedigrees have been published. On the other hand Axenfeld, Fuchs, von Hippel, Treacher Collins and others, thought that the two conditions were different manifestations of the same disease. Zorab ${ }^{2}$ describes a case of megalocornea affecting one eye and hydrophthalmia the other. His description is insufficient, but I feel that the megalocornea was also an arrested hydrophthalmia.

The possibility of Dvr. H. being a megalocornea with juvenile glaucoma affecting the right eye is most unlikely. The lack of symmetry, the wide limbus, the thin sclera, and definite glaucoma, right, all support the contention that this is a case of hydrophthalmia, although the freedom of the corneae from the typical splits of Descemet and opacities is unexpected.

\section{Summary and Conclusion}

$A$ case is described with many features which might have suggested diagnosis of megalocornea, but has declared itself as hydrophthalmia. It indicates that the diagnosis of the former condition in the absence of a familial history can be most difflcult and should then be made reservedly.

\section{REFERENCES}

1. ANDERSON, J. RINGLAND- "Hydrophthalmia or Congenital Glaucoma," 1939 .

2. ZoraB, A.-Trans. Ophthal. Soc. U.K., Vol. XI, p. 139, 1930.

\section{AN ELECTROLYSIS APPARATUS DEVISED FOR RETINAL DETACHMENTS*}

BY

\section{G. GORDON-NAPIER \\ NOTTINGHAM}

ELECTROLYSIS was originally used by Schoeler (1893) and Abadie (1893) in the treatment of detachment of the retina but without any success chiefly because they did not search for, find and seal the retinal tear. v. Szily and Machemer in 1934 used bipolar electrolysis with success. Imre used the anodal in 1932 and Vogt the cathodal current in 1934.

- Paper read before the Midland Ophthalmological Society at Nottingham on Tuesday, March 26, 1946. 